
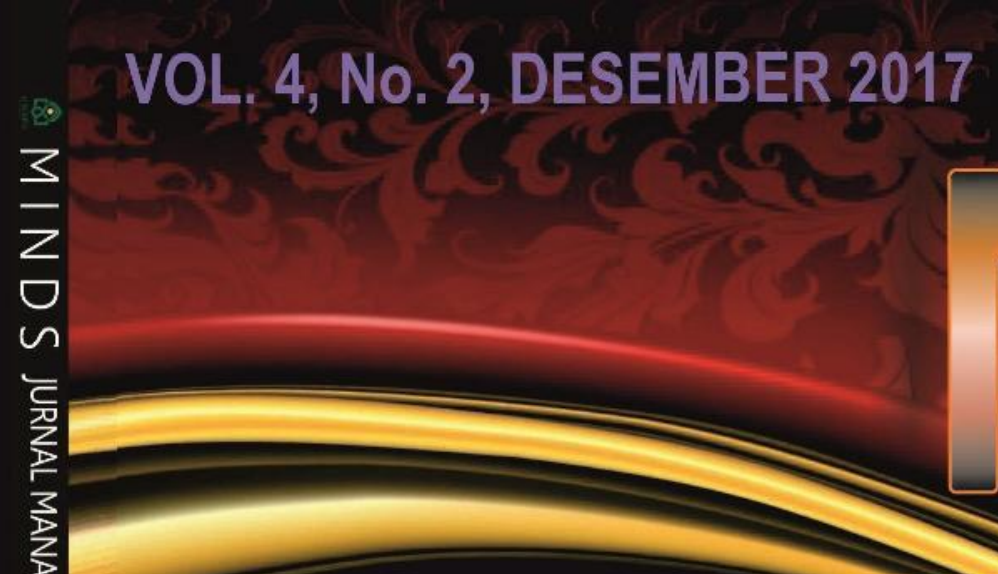

ShI

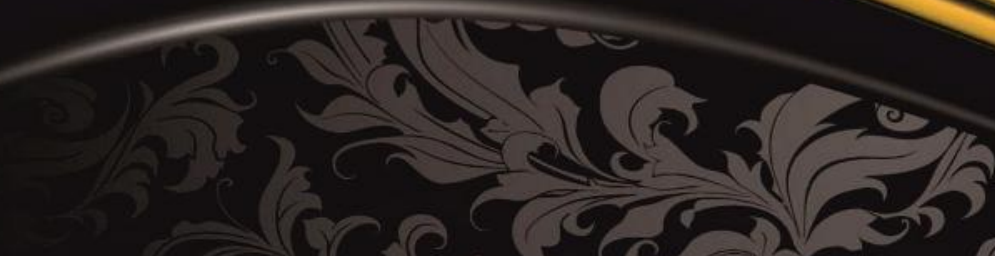

(ब)
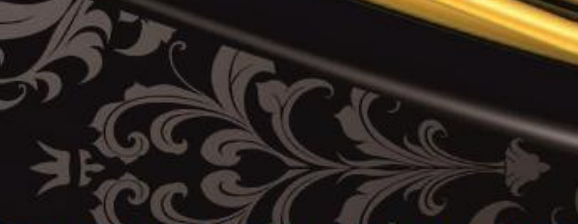

(C)

IDENTIFIKASI GAYA KEPEMIMPINAN PADA ORGANISASI RELAWAN PENANGGULANGAN BENCANA DI JAWA TIMUR

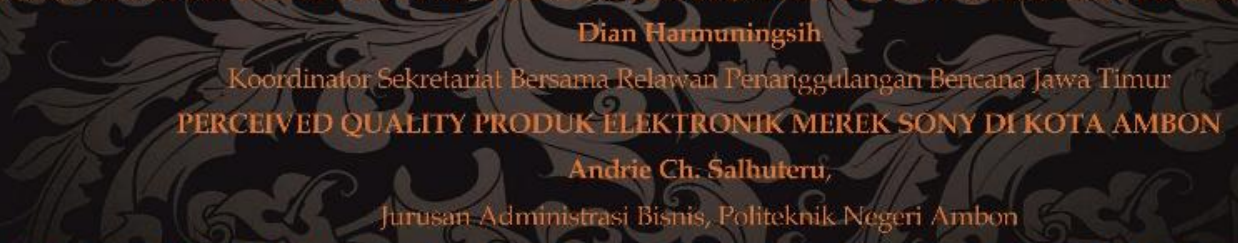

PENGARUH PROFITABILITAS, UIKUIDITAS, LEVERAGE, DAN FIRM SIZE TERHADAP KEBIJAKAN DIVIDEN PERUSAHAAN

$$
\begin{aligned}
& \text { DI INDEKS JII, PERIODE 2011-2015 } \\
& \text { Rika Dwi Ayu Parmitasari \& Hasrianto, }
\end{aligned}
$$

Jurusan Manajemen Fakultas Ekonomi dan Bisnis Islam, UIN Alauddin Makassar

FAKTOR YANG MEMENGARUHI KEPUASAN NASABAH BANK MUAMALAT CABANG AMBON

$$
\text { Gilman Pary, }
$$

Institut Agama Islam Negeri Ambon,

PENGARUH ATRIBUT PRODUK DAN PERILAKU PENCARIAN VARIASI TERHADAP PERILAKU MAHASISWA BERPINDAH MEREK PONSEL PADA FAKULTAS EKONOMI DAN BISNIS ISLAM Jusmiati \& Ahmad Efendi,

Jurusan Manajemen, Fakultas Ekonomi dan Bisnis Islam, UIN Alauddin Makassar

PENGARUH KUALITAS LAYANAN TERHADAP KEPUASAN PELANGGAN RUTE DOMESTIK GARUDA INDONESIA DI KOTA AMBON Saul Ronald Jacob Saleky,

Jurusan Administrasi Bisnis, Politeknik Negeri Ambon

PENGARUH STRES KERJA DAN IKLIM ORGANISASI TERHADAP TURNOVER KARYAWAN

$$
\text { Ludy Sapulette, }
$$

Jurusan Administrasi Bisnis, Politeknik Negeri Ambon

PENGARUH PEMBERDAYAAN DAN BUDAYA ORGANISASI TERHADAP PROFESIONALISME DOSEN

Ady Andardinata,

STIE Tri Dharma Nusantara

PENGARUH CSR, FIRM SIZE DAN INTEREST-BASED DEBT TERHADAP NILAI PERUSAHAAN PADA PERUSAHAAN MANUFAKTUR DI INDEKS JII, PERIODE 2010-2016

Wahidah Abdullah, Alim Syariati, \& Reskianti hamid

Fakultas Ekonomi dan Bisnis Islam, UNN Alauddin Makassar

ANALISIS DIMENSI KUALITAS PELAYANAN TERHADAP KEPUASAAN PASIEN PADA RSUD SYEKH YUSUF SUNGGUMINASA Asdi,

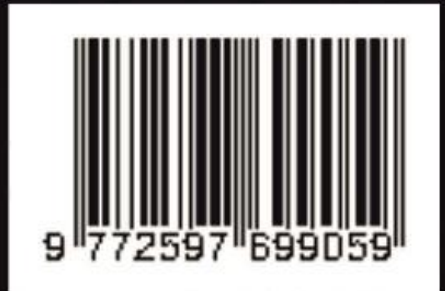

FEB, Lniversitas Muhammadiyah Makassar 
[Type text]

\section{KATA PENGANTAR}

Assalamualaikum WR. WB.

Puja dan puji syukur mari kita panjatkan ke hadirat Allah SWT, karena atas berkah dan karunia-Nya, maka Jurnal Manajemen dan Inspirasi (MINDS), Jurusan Manajemen, Fakultas Ekonomi dan Bisnis Islam, UIN Alauddin Makassar ini dapat diselesaikan. Salam dan shalawat kita haturkan kepada Nabi Muhammad SAW, sang pelita di tengah kejumudan dan kejahiliyahan, serta sumber informasi dan inspirasi yang terpercaya, al-Amiin. Terima kasih kami sampaikan kepada seluruh pihak yang terlibat dalam penyusunan jurnal Minds dari awal hingga akhir yang tidak dapat kami sebutkan satu persatu.

Adapun jurnal Minds merupakan titik kulminasi perwujudan kemampuan menulis tenaga pendidik yang berada di intra Fakultas maupun luar universitas. Tulisan akademik yang diharapkan menjadi contoh nyata jawaban dari berbagai fenomena empiris yang relevan dari sisi keilmuan Manajemen. Edisi kali ini, yaitu Vol. 4, No.2, 2017, mengupayakan adanya pengembangan dari sisi kualitas tulisan maupun sebaran wilayah penulis. Upaya ini diharapkan akan mendorong terciptanya proses yang lebih terukur baik dari penulis, mitra bestari, maupun penyunting, sehingga peningkatan kualitas publikasi ilmiah dapat diharapkan sebagai keluaran yang pasti.

Seiring dengan penerbitan jurnal ini, maka mewakili tim publikasi, saya menyampaikan rasa terima kasih yang sebesar-besarnya untuk seluruh penulis yang berpartisipasi dalam edisi kali ini, dan kepada para pembaca yang telah berkenan meluangkan waktunya untuk menelaah tulisan-tulisan yang termuat pada edisi kali ini.

Wassalamualaikum WR.WB.

Manajer Jurnal,

Dr. Alim Syariati, SE., M.Si. 


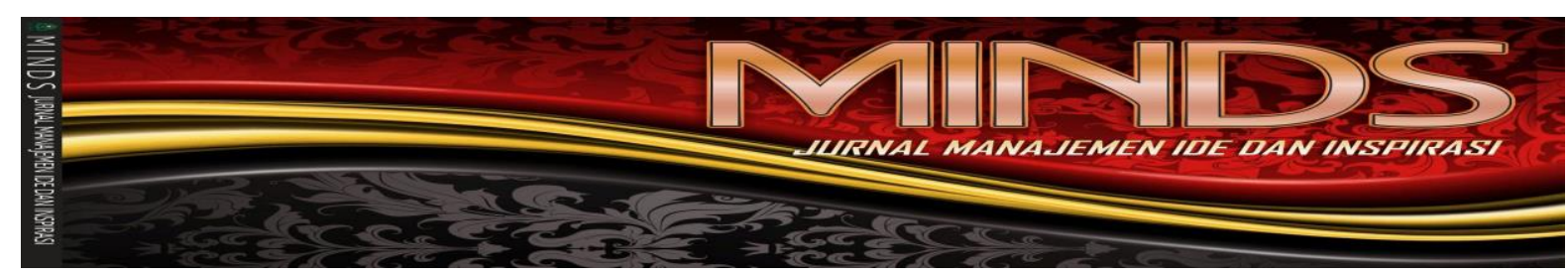

\section{DAFTAR ISI}

IDENTIFIKASI GAYA KEPEMIMPINAN PADA ORGANISASI

RELAWAN PENANGGULANGAN BENCANA DI JAWA TIMUR......

Dian Harmuningsih

Koordinator Sekretariat Bersama Relawan Penanggulangan Bencana Jawa Timur

PERCEIVED QUALITY PRODUK ELEKTRONIK MEREK SONY

DI KOTA AMBON

Andrie Ch. Salhuteru,

Jurusan Administrasi Bisnis, Politeknik Negeri Ambon

PENGARUH PROFITABILITAS, LIKUIDITAS, LEVERAGE, DAN

UKURAN PERUSAHAAN TERHADAP KEBIJAKAN DIVIDEN

SAHAM-SAHAM YANG TERDAFTAR PADA

JAKARTA ISLAMIC INDEX (JII) PERIODE TAHUN 2011-2015........

Rika Dwi Ayu Parmitasari \& Hasrianto,

Jurusan Manajemen Fakultas Ekonomi dan Bisnis Islam, UIN Alauddin Makassar

FAKTOR YANG MEMENGARUHI KEPUASAN NASABAH

BANK MUAMALAT CABANG AMBON

Gilman Pary,

Institut Agama Islam Negeri Ambon,

PENGARUH ATRIBUT PRODUK DAN PERILAKU PENCARIAN

VARIASI TERHADAP PERILAKU MAHASISWA BERPINDAH MEREK

PONSEL PADA FAKULTAS EKONOMI DAN BISNIS ISLAM............

Jusmiati \& Ahmad Efendi,

Jurusan Manajemen, Fakultas Ekonomi dan Bisnis Islam, UIN Alauddin Makassar

PENGARUH KUALITAS LAYANAN TERHADAP KEPUASAN PELANGGAN RUTE DOMESTIK GARUDA INDONESIA DI KOTA AMBON

Saul Ronald Jacob Saleky,

Jurusan Administrasi Bisnis, Politeknik Negeri Ambon

PENGARUH STRES KERJA DAN IKLIM ORGANISASI TERHADAP

TURNOVER INTENTION

Ludy Sapulette,

Jurusan Administrasi Bisnis, Politeknik Negeri Ambon

PENGARUH PEMBERDAYAAN DAN BUDAYA ORGANISASI

TERHADAP PROFESIONALISME DOSEN.

Ady Andardinata,

STIE Tri Dharma Nusantara 
PENGARUH CORPORATE SOCIAL RESPONSIBILITY (CSR), UKURAN PERUSAHAAN DAN INTEREST BASED DEBT (IBD) TERHADAP NILAI PERUSAHAAN PADA PERUSAHAAN MANUFAKTUR (YANG TERDAFTAR DI JAKARTA ISLAMIC INDEX PERIODE 2010-2016)..... Wahidah Abdullah, Alim Syariati, \& Reskianti hamid

Fakultas Ekonomi dan Bisnis Islam, UIN Alauddin Makassar

ANALISIS DIMENSI KUALITAS PELAYANAN TERHADAP KEPUASAAN PASIEN PADA RSUD SYEKH YUSUF SUNGGUMINASA

Asdi, FEB,

Universitas Muhammadiyah Makassar 


\title{
PENGARUH CORPORATE SOCIAL RESPONSIBILITY (CSR), UKURAN \\ PERUSAHAAN DAN INTEREST BASED DEBT (IBD) TERHADAP NILAI PERUSAHAAN PADA PERUSAHAAN MANUFAKTUR DI JAKARTA ISLAMIC INDEX PERIODE 2010-2016
}

\author{
Wahidah Abdullah, Alim Syariati ${ }^{*}$, \& Reskianti Hamid
}

\begin{abstract}
ABSTRAK
Pada dasarnya semua perusahaan harus dihadapkan dengan modal yang akan menentukan keberlanjutan hidup perusahaannya, modal ini dapat diperoleh apabila sang investor tertarik untuk berinvestasi pada perusahaan, salah satu cara agar investor tertarik pada perusahaan dapat dilihat dari nilai perusahaannya. Nilai perusahaan merupakan persepsi investor terhadap tingkat keberhasilan perusahaan yang sering dikaitkan dengan Harga saham. Harga saham yang tinggi membuat nilai perusahaan juga tinggi.

Penelitian ini bertujuan untuk menguji pengaruh dari 3 komponen yaitu corporate social responsibility, Ukuran Perusahaan dan Interest Based Debt terhadap Nilai Perusahaan pada perusahaan manufaktur yang Terdaftar di Jakarta Islamic Index. Variabel yang digunakan dalam penelitian ini yaitu corporate social responsibility,Ukuran Perusahaan dan Intrest Based Debt sebagai variabel independen serta Nilai Perusahaan sebagai Variabel Dependen.

Jenis penelitian ini adalah penelitian kuantitatif, sumber data dalam penelitian ini yaitu data sekunder yang diperoleh dari JII. Jumlah sampel yang digunakan dalam penelitian sebanyak 7 perusahaan manufaktur. Metode pemilihan sampel yang digunakan yaitu metode nonprobabilitas yaitu purposive sampling yang merupakan teknik pengambilan sampel berdasarkan kriteria tertentu yang ditentukan oleh peneliti. Teknik analisis data yang digunakan yaitu regresi linear berganda.

Hasil dari pengujian hipotesis didalam penelitian ini menunjukkan bahwa CSR berpengaruh positif dan signifikan pada Nilai Perusahaan, ukuran perusahaan berpengaruh negatif dan signifikan, sedangkan Interest Based Debt berpengaruh positif dan signifikan terhadap nilai perusahaan
\end{abstract}

Kata kunci :Nilai Perusahaan, Corporate Social Responsibility, Ukuran Perusahaan dan Interest-Based Debt

\footnotetext{
${ }^{*}$ Fakultas Ekonomi dan Bisnis Islam, UIN Alauddin Makassar, (alim.syariati@gmail.com)
} 


\section{PENDAHULUAN}

Perkembangan bisnis di Indonesia saat ini bergerak dengan pesat, hal ini ditandai dengan banyaknya perusahaan baru yang bermunculan, sehingga tercipta persaingan usaha yang semakin ketat. Pekerjaan dibidang bisnis pada masa lalu belum mampu menarik perhatian anak muda saat itu, berbanding terbalik dengan masa sekarang. Hal ini tidak terlepas dari latar belakang pekerjaan bisnis di negara kita yang pada saat itu masih kurang menguntungkan. Hughes dan Kapoor menyatakan bahwa bisnis ialah suatu kegiatan individu yang terorganisir untuk menghasilkan dan menjual barang atau jasa guna mendapatkan keuntungan dalam memenuhi kebutuhan masyarakat.

Meskipun industri manufaktur mendapat perhatian lebih dari pemerintah tapi perusahaan manufaktur hingga saat ini masih menghadapi beberapa kendala seperti masalah permodalan, infrastruktur, dan tentu saja persoalan ketenagakerjaan atau buruh. Minat para investor untuk menanamkan modalnya pada perusahaan ini juga sering kali menjadi masalah pelik yang dihadapi.

Kendala atau masalah ini pun tak luput dari perusahaan manufaktur yang terdaftar di Jakarta Islamic index (JII). Ketertarikan investor untuk menanamkan modalnya menjadi perhatian utama bagi perusahaan dan salah satu cara agar investor tertarik pada perusahaan tersebut dapat dilihat dari nilai perusahaan yang tercermin pada harga sahamnya. Banyak perusahaan demi meningkatkan nilai perusahaan mereka rela melakukan segala cara agar perusahaan mereka dapat terlihat menarik dimata investor, mereka tidak menyadari bahwa hal ini dapat berakibat buruk pada keberlangsungan hidup perusahaan dimasa yang akan datang. Pengharapan dimasa sekarang akan mempengaruhi perusahaan dimasa depan jadi kebijakan yang diambil saat ini harus memperhitungkan keuntungan dimasa depan.

Perlunya tanggung jawab sosial dalam suatu perusahaan dapat memberikan pemahaman betapa pentingnya suatu etika dalam dunia usaha yang bertujuan mendorong mereka agar dapat mengelola perusahaannya lebih dinamis dan bertanggung jawab. Sanksi pidana mengenai pelanggaran CSR pun terdapat di dalam Undang-Undang Nomor 40 Tahun 2007 tentang Perseroan Terbatas, pasal 1tentang perseroan terbatas menyebutkan "tanggung jawab social dan lingkungan adalah komitmen perseroan untuk berperan serta dalam pembangunan ekonomi berkelanjutan guna meningkatkan kualitas kehidupan dan lingkungan yang bermanfaat, baik bagi perseroan sendiri, komunitas setempat maupun masyarakat pada umumnya".

Selain CSR faktor lain yang dapat mempengaruhi nilai perusahaan adalah ukuran perusahaan. Ukuran perusahaan (size) merupakan suatu indikator yang menunjukkan kekuatan finansial perusahaan. Ukuran perusahaan dianggap mampu mempengaruhi nilai perusahaan karena semakin besar ukuran atau skala perusahaan maka akan semakin mudah pula perusahaan memperoleh sumber 
pendanaan baik yang bersifat internal maupun eksternal. Ukuran perusahaan merupakan hal yang penting dalam proses pelaporan keuangan.

Nilai perusahaan dapat pula dipengaruhi oleh Interest Based Debt (Hutang Berbasis Bunga). Interest baseb debt atau utang bank juga merupakan salah satu syarat yang dimiliki oleh pihak JII dalam memilih saham yang layak masuk daftar sahamnya. Salah satu syarat agar saham masuk daftar saham syariah di JII adalah seleksi berdasarkan komposisi sumber pembiayaan yang berasal dari sumber non halal atau pinjaman berbasis bunga dibandingkan modal perusahaan. Saat ini, persentase yang berlaku di pasar modal syariah Indonesia untuk komposisi hutang berbasis bunga terhadap modal perusahaan adalah tidak lebih besar dari $82 \%$. Artinya, Rasio utang berbasis bunga adalah (modal 55\% dan utang $45 \%$ ).

\section{TINJAUAN PUSTAKA}

Manajemen sering didefenisikan sebagai seni untuk melaksanakan suatu pekerjaan melalui orang lain. Artinya bahwa para manajer mencapai tujuan organisasi dengan cara mengatur orang lain. Manajemen keuangan merupakan kegiatan yang meliputi kegiatan perencanaan, analisis dan pengendalianpengendalian kegiatan keuangan dimana pelaksana kegiatan tersebut dinamakan manajer keuangan. Manajer harus mencari sumber dana untuk menyesuaikan kas yang diperlukan, pemenuhan kas di dalam perusahaan merupakan tanggung jawab manajemen keuangan.

Tujuan manajemen keuangan berkaitan dengan keputusan di bidang keuangan untuk memaksimumkan nilai perusahaan. Kemakmuran para pemegang saham diperlihatkan dalam wujud semakin tingginya harga saham yang merupakan cerminan dari keputusan-keputusan investasi pendanaan dan kebijakan deviden. Jadi semakin tinggi nilai sahamnya, maka semakin tinggi pula nilai perusahaannya (Kasmir, 2016).

Pada tujuan pemilik adalah selalu memaksimalkan laba, untuk mencapai tujuan memaksimalkan laba para manajer keuangan mengambil tindakan yang diharapkan dapat memberikan kontribusi untuk peningkatan keseluruhan laba perusahaan. Kelompok yang berkepentingan adalah kelompok seperti karyawan, pelanggan, kreditur dan pihak lainnya yang memiliki hubungan dengan ekonomi perusahaan (Raprayogha, Rusnawati, \& Abbas, 2017).

\section{Nilai Perusahaan}

Menurut Brigham dan Houston (2007), nilai perusahaan merupakan harga yang bersedia dibayar oleh calon pembeli apabila perusahaan tersebut dijual. Sedangkan menurut Fama nilai perusahaan dapat dilihat dari harga sahamnya.

Menurut Sujoko dan Subiantoro (2007), nilai perusahaan merupakan persepsi investor terhadap tingkat keberhasilan perusahaan yang sering dikaitkan dengan harga saham. Harga saham yang tinggi membuat nilai perusahaan juga tinggi. nilai perusahaan yang tinggi akan membuat pasar percaya tidak hanya pada kinerja perusahaan saat ini namun juga pada prospek perusahaan di masa depan (Said \& Muhammad H. 2016). 
Menurut Cristiawan dan Tarigan (2007), terdapat beberapa konsep nilai yang menjelaskan nilai suatu perusahaan antara lain:

1. Nilai nominal, yaitu nilai yang tercantum secara formal dalam anggaran dasar perseroan, disebutkan secara eksplisit dalam neraca perusahaan dan ditulis secara jelas dalam surat saham kolektif.

2. Nilai pasar, sering disebut kurs adalah harga yang terjadi dari proses tawar menawar dipasar saham. Nilai ini hanya bisa ditentukan jika saham perusahaan dijual di pasar saham.

3. Nilai intrinsik, merupakan nilai yang mengacu pada perkiraan nilai riil suatu perusahaan. Nilai perusahaan dalam konsep nilai intrisik bukan sekedar harga dari sekumpulan aset, melainkan nilai perusahaan sebagai entitas bisnis yang memiliki kemampuan menghasilkan keuntungan dikemudian hari.

\section{Corporate Social Responsibility}

Secara konseptual CSR adalah sebuah pendekatan dimana perusahaan mengintegrasikan kepedulian sosial dalam operasi bisnis mereka dan dalam interaksi mereka dengan pemangku kepentingan (stakeholders) berdasarkan prinsip kesukarelaan, artinya pihak perusahaan harus melihat jika CSR bukan program pemaksaan tapi bentuk rasa kesetiakawanan terhadap sesama umat manusia (Syariati, 2012).

Zainal Arifin mengatakan sudah saatnya perusahaan yang bergerak di sumber daya alam untuk merubah paradigma yang awalnya " $5 \mathrm{P}$ ", (product, price, promisition, pleace and profit) menjadi " $3 \mathrm{P}$ ", yaitu planet, people dan profit. Perusahaan tidak hanya sekedar mencari laba (profit), tetapi lebih dari itu mereka juga berikhtiar dalam menyejahterakan orang (people), dan menjamin keberlanjutan hidup planet ini (planet) (dalam Fajar, 2013:188).

Manfaat Corporate Social Responsibility (CSR) bagi perusahaan antara lain: (a) mempertahankan serta mendongkrak reputasi citra perusahaan, (b) mendapatkan lisensi untuk beroperasi secara sosial, (c) melebarkan akses sumber daya bagi operasional usaha, (d) membuka peluang pasa yang lebih luas, (e) memperbaiki hubungan dengan stakeholder, (f) meningkatkan semangat dan produktivitas karyawan, (g) mereduksi risiko perusahaan, (h) peluang mendapatkan penghargaan. Manfaat lain yang akan dirasakan oleh pihak perusahaan dengan menerapkan CSR berdampak jangka panjang. Teori yang berhubungan dengan CSR yaitu (Fahmi, 2014:8):

a). Teori legitimasi (legitimacy theory),

b). Teori stakeholder

c). Teori persinyalan (signaling theory),

Crowther dalam Meita membagi menjadi tiga atas prinsip-prinsip tanggung jawab sosial, yaitu:

1. Sustainability,

2. Accountability

3. Transparency 


\section{Ukuran Perusahaan}

Moh'd, Perry, \& Rimbey (1998, dalam Sri Hasnawati, 2015) mengemukakan bahwa perusahaan yang berukuran besar akan lebih mudah mengakses pendanaan melalui pasar modal. Kemudahan ini merupakan informasi baik bagi pengambilan keputusan investasi dan juga dapat merefleksikan nilai perusahaan di masa mendatang. Ukuran perusahaan menggambarkan besar kecilnya suatu perusahaan yang dapat dinyatakan dengan total aktiva atau total penjualan bersih. Semakin besar total aktiva maupun penjualan, maka semakin besar pula ukuran suatu perusahaan.

Menurut Weston dan Brigham (1990, dalam Hazlina \& Suwito, 2016) menyatakan bahwa suatu perusahaan yang besar dan mapan (stabil) akan lebih mudah untuk ke pasar modal. Kemudahan untuk ke pasar modal maka berarti fleksibilitas bagi perusahaan besar lebih tinggi serta kemampuan untuk mendapatkan dana dalam jangka pendek juga lebih besar daripada perusahaan kecil. Ukuran perusahaan secara langsung mencerminkan tinggi rendahnya aktivitas operasi suatu perusahaan. Pada umumnya semakin besar suatu perusahaan maka akan semakin besar pula aktivitasnya. Dengan demikian, ukuran perusahaan juga dapat dikaitkan dengan besarnya kekayaan yang dimiliki oleh perusahaan.

\section{Interst Based Debt}

Hutang adalah pengorbanan manfaat ekonomi yang akan timbul dimasa yang akan datang yang disebabkan oleh kewajiban di saat sekarang dari suatu badan usaha yang akan dipenuhi dengan mentransfer aktiva atau memberikan jasa kepada badan usaha lain dimasa datang sebagai akibat dari transaksitransaksi yang sudah lalu. Sedangkan bunga adalah balas jasa yang diberikan nasabah kepada bank, atau dengan kata lain adalah harga yang harus dibayar oleh nasabah atas pemakaian dana yang diberikan oleh bank.

Interst Based Debt atau utang bank adalah merupakan sejumlah uang yang diperoleh perusahaan secara pinjaman dari perbankan dan pembayarannya dilakukan secara angsuran sesuai perjanjian kedua belah pihak. Interst Based Debt juga merupakan salah satu persyaratan yang di tetapkan oleh pihak JII dalam menyeleksi perusahaan yang layak masuk daftar saham syariah. Pendapat Modigliani and Miller menyatakan bila ada pajak penghasilan perusahaan maka penggunaan hutang akan meningkatkan nilai perusahaan karena biaya bunga hutang adalah biaya yang mengurangi pembayaran pajak (tax deductable expense) (Sartono, 2016: 15).

Hutang merupakan salah satu sumber pembiayaan eksternal yang digunakan oleh perusahaan untuk membiayai kebutuhan dananya. Dalam pengambilan keputusan akan penggunaan hutang ini harus mempertimbangkan besarnya biaya tetap yang muncul dari hutang berupa bunga yang akan menyebabkan semakin meningkatnya leverage keuangan dan semakin tidak 
pastinya tingkat pengembalian bagi para pemegang saham biasa. Persentase dari pokok utang yang dibayarkan sebagai imbal jasa (bunga) dalam suatu periode tertentu disebut "suku bunga".

\section{METODOLOGI PENELITIAN}

\section{Jenis Penelitian}

Penelitian ini merupakan penelitian kuantitatif, yakni kegiatan penelitian dalam usaha pencapaian kesimpulan atas hipotesis yang diajukan dengan melakukan analisis data-data kuantitatif. Metode penelitian kuantitatif dapat diartikan sebagai metode penelitian yang berlandaskan pada filsafat positivisme, digunakan untuk meneliti pada populasi atau sampel tertentu. Data kuantitatif merupakan data-data yang disajikan dalam bentuk angka-angka.

\section{Lokasi dan Waktu Penelitian}

Penelitian ini dilakukan pada Bursa Efek Indonesia (BEI) dengan mengambil data dikantor perwakilan Bursa Efek Indonesia yaitu PT. IDX Cabang Makassar yang berlokasi di jalan A.P. Pettarani 18 A-4 Makassar. Adapun target waktu penelitian selama \pm 3 bulan yaitu pada bulan Agustus - Oktober 2017

\section{Populasi dan Sampel}

Populasi dalam penelitian ini ada tiga puluh (30) perusahaan manufaktur yang terdaftar di JII selama tahun 2010-2016. Teknik pengambilan sampel yang digunakan adalah purposive sampling. Purposive sampling adalah teknik yang digunakan apabila anggota sampel yang dipilih secara khusus berdasarkan tujuan penelitiannya.

\section{Metode Pengumupulan Data}

Sesuai dengan jenis data yang diperlukan yaitu data sekunder, maka metode pengumpulan data dalam penelitian ini adalah dengan menggunakan metode studi kepustakaan dan studi observasi. Metode studi kepustakaan yaitu suatu cara yang dilakukan dimana dalam memperoleh data dengan menggunakan cara membaca dan mempelajari buku-buku yang berhubungan dengan masalah yang dibahas dalam lingkup penelitian ini. Sedangkan metode studi observasi yaitu suatu cara memperoleh data dengan menggunakan dokumentasi yang berdasarkan pada laporan keuangan yang telah dipublikasikan oleh Bursa Efek Indonesia.

\section{HASIL DAN PEMBAHASAN \\ Uji Asumsi Klasik}

Pengujian Normalitas dilakukan dengan menggunakan teknik KolmogorovSmirnov dengan bantuan SPSS. Data yang baik dan layak digunakan dalam penelitian adalah data yang memiliki distribusi normal. Jika nilai significant (Sig.) lebih besar dari 5\% maka dapat disimpulkan bahwa residual menyebar normal, dan jika nilai significant (Sig.) lebih kecil dari 5\% maka dapat disimpulkan bahwa residual menyebar tidak normal. Adapun hasil uji normalitas adalah sebagai berikut : 
Tabel 4.1 Hasil Uji Normalitas

One-Sample Kolmogorov-Smirnov Test

\begin{tabular}{|c|c|c|}
\hline & & $\begin{array}{l}\text { Standardize } \\
\text { d Residual }\end{array}$ \\
\hline \multicolumn{2}{|l|}{$\mathrm{N}$} & 49 \\
\hline \multirow{4}{*}{$\begin{array}{l}\text { Normal } \\
\text { Parametersa,b }\end{array}$} & Mean & 0E-7 \\
\hline & Std. & \\
\hline & Deviation & .96824584 \\
\hline & Absolute & .183 \\
\hline \multirow{2}{*}{$\begin{array}{l}\text { Most } \\
\text { Differences }\end{array}$} & Positive & .183 \\
\hline & Negative & -.079 \\
\hline \multirow{2}{*}{\multicolumn{2}{|c|}{$\begin{array}{l}\text { Kolmogorov-Smirnov Z } \\
\text { Asymp. Sig. (2-tailed) }\end{array}$}} & 1.282 \\
\hline & & .075 \\
\hline
\end{tabular}

Sumber: Data Diolah (Output SPSS), 2017

Berdasarkan tabel uji normalitas dapat dilihat bahwa Sig. (2-tailed) untuk data variabel CSR, Ukuran Perusahaan, Interest Based Debt terhadap Nilai Perusahaan adalah 0,075. Jika digunakan $\alpha=0,05$ maka dapat disimpulkan bahwa data terdistribusi normal karena 0,075>0,05.

\section{Uji Multikolinearitas}

Multikolinearitas dapat juga dilihat dari nilai Tolerance dan lawannya Variance Inflation Factor (VIF). Kedua ukuran ini menunjukkan setiap variabel bebas manakah yang dijelaskan oleh variabel bebas lainnya. Tolerance mengukur variabilitas variabel bebas yang terpilih yang tidak dapat dijelaskan oleh variabel bebas lainnya. Jadi nilai tolerance rendah sama dengan nilai VIF tinggi (karena VIF $=1 /$ tolerance ) dan menunjukkan adanya kolinearitas yang tinggi. Nilai cutoff yang umum dipakai adalah nilai tolerance di atas 0,10 atau sama dengan nilai VIF dibawah 10.

Tabel 4.2

Hasil Uji Multikolinearitas

Coefficients(a)

\begin{tabular}{|ll|l|l|}
\hline \multirow{2}{*}{ Model } & \multicolumn{2}{|l|}{ Collinearity Statistics } \\
\cline { 3 - 4 } & & Tolerance & VIF \\
\hline 1 & (Constant) & .900 & 1.111 \\
& CSR & .955 & 1.047
\end{tabular}


Dependent Variable: Nilai Perusahaan (data diolah)

Berdasarkan Tabel di atas, dapat kita lihat bahwa setiap variabel independen memiliki nilai Tolerance (TOL) $\geq 0,1$. Nilai VIF untuk masing-masing variabel penelitian sebagai berikut :

a. Nilai VIF untuk variabel CSR sebesar $1.111<10$, sehingga variabel CSR dinyatakan tidak terjadi gejala multikolinearitas.

b. Nilai VIF untuk variabel Ukuran Perusahaan sebesar $1.047<10$, sehingga variabel Ukurn Perusahaan dinyatakan tidak terjadi gejala multikolinearitas.

c. Nilai VIF untuk variabel IBD sebesar $1.076<10$, sehingga variabel IBD dinyatakan tidak terjadi gejala multikolinearitas.

\section{Uji Heteroskedastisitas}

Uji Heteroskedastisitas bertujuan untuk menguji apakah dalam model regresi terjadi ketidaksamaan variance dari residual pengamatan satu ke pengamatan yang lain berbeda. Sedangkan bila terjadi ketidaksamanan variance dari residual pengamatan satu ke pengamatan yang lain tetap maka disebut homokedastisitas. Model regresi yang baik adalah yang homokedastisitas atau tidak terjadi heteroskedastisitas.

\section{Gambar 4.1}

\section{Hasil Uji Heteroskedastisitas}

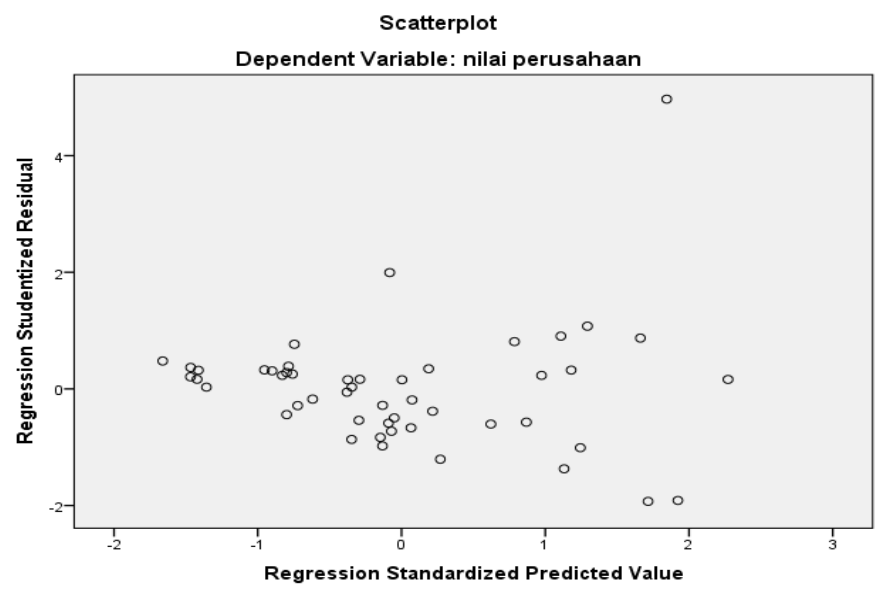

Berdasarkan Gambar diatas, dapat diketahui bahwa data (titik-titik) menyebar secara merata di atas dan di bawah garis nol, tidak berkumpul di satu tempat, serta tidak membentuk pola tertentu sehingga dapat disimpulkan bahwa pada uji regresi ini tidak terjadi masalah heteroskedastisitas.

\section{Uji Auto Korelasi}


Model regresi yang baik adalah yang bebas dari autokorelasi. Pengujian ini digunakan untuk menguji asumsi klasik regresi berkaitan dengan adanya autokorelasi. Pengujian ini menggunakan Durbin Watson (DW-test).

\section{Tabel 4.3}

\section{Hasil Uji Autokorelasi Model Summary(b)}

\begin{tabular}{|c|c|c|c|c|c|}
\hline $\begin{array}{l}\text { Mode } \\
1\end{array}$ & $R$ & $\begin{array}{l}\mathrm{R} \\
\text { Square }\end{array}$ & $\begin{array}{l}\text { Adjusted } \quad R \\
\text { Square }\end{array}$ & $\begin{array}{l}\text { Std. Error of the } \\
\text { Estimate }\end{array}$ & Durbin-Watson \\
\hline 1 & $.685^{\mathrm{a}}$ & .470 & .434 & 284.12737 & 1.862 \\
\hline
\end{tabular}

a. Predictors: (Constant), Hutang berbasis bunga, Ukuran peruahaan, CSR b. Dependent Variable: Nilai perusahaan

Pada tabel diatas dilihat bahwa nilai Durbin-Watson sebesar 1.862 karena nilai DW berkisar antara 1,65 $<2,35$, maka dapat disimpulkan bahwa tidak terjadi masalah autokorelasi pada model regresi, sehingga model regresi layak untuk digunakan dalam melakukan pengujian.

\section{Hasil Uji Analisis Regresi Linier Berganda}

Persamaan regresi dapat dilihat dari tabel hasil uji coefficients berdasarkan output SPSS terhadap ketiga variabel independen yaitu CSR, Ukuran Perusahaan, Hutang Berbasis Bunga terhadap Nilai Perusahaaan ditunjukkan pada tabel berikut:

Tabel 4.4

\section{Hasil Uji Regresi Berganda \\ Coefficients (a)}

Coefficients ${ }^{a}$

\begin{tabular}{|c|c|c|c|c|c|c|}
\hline \multirow{2}{*}{\multicolumn{2}{|c|}{ Model }} & \multicolumn{2}{|c|}{$\begin{array}{c}\text { Unstandardized } \\
\text { Coefficients }\end{array}$} & \multirow{2}{*}{$\begin{array}{c}\begin{array}{c}\text { Standardize } \\
\mathrm{d} \\
\text { Coefficients }\end{array} \\
\text { Beta }\end{array}$} & \multirow[t]{2}{*}{$\mathrm{t}$} & \multirow[t]{2}{*}{ Sig. } \\
\hline & & B & Std. Error & & & \\
\hline \multirow{4}{*}{1} & (Constant) & 4787.558 & 938.569 & & 5.101 & .000 \\
\hline & Csr & 919.182 & 443.494 & 237 & 2.073 & .044 \\
\hline & ukuran perusahaan & -164.953 & 31.342 & -.585 & 5263 & .000 \\
\hline & hutang berbasis bunga & 4414.153 & 1389.361 & .358 & 3.177 & .003 \\
\hline
\end{tabular}

a. Dependent Variable: nilai perusahaan

Berdasarkan tabel di atas maka model regresi yang digunakan adalah sebagai berikut:

Nilai Perusahaan $=4787.558+919.182 X 1-164.953 X 2+4414.153 X 3+\mathrm{e}$ 
Dari persamaan regresi linier berganda diatas, diketahui mempunyai konstanta sebesar, 4787.558 diartikan bahwa Nilai Perusahaan mempunyai nilai sebesar 4787.558 jika variabel seperti CSR, Ukuran Perusahaan dan IBD adalah tidak ada atau dianggap konstant.

Berdasarkan persamaan regresi dari tabel 4.5, maka hasil regresi linear berganda dapat disimpulkan sebagai berikut :

1. Koefisien variabel CSR $=919.182$ dengan tanda positif berarti setiap kenaikan CSR sebesar satu satuan akan menyebabkan kenaikan Nilai Perusahaan sebesar 919.182.

2. Koefisien variabel Ukuran Perusahaan sebesar 164.953 dengan tanda negatif artinya jika Ukuran Perusahaan mengalami kenaikan sebesar satu satuan maka Nilai Perusahaan akan menurun sebesar 164.953.

3. Koefisien variabel $\mathrm{IBD}=4414.153$ dengan tanda positif menunjukkan bahwa setiap terjadi kenaikan IBD sebesar satu satuan maka Nilai Perusahaan akan mengalami kenaikan sebesar 4414.153.

\section{Hasil uji f (Simultan)}

Uji statistik $\mathrm{f}$ atau Analisis Of Variance (ANOVA) digunakan untuk menguji masing-masing variabel bebas berpengaruh secara signifikan terhadap variabel terikat secara bersama-sama dengan $\alpha=0,05$ dan menerima atau menolak hipotesis. Hasil perhitungan uji f dapat dilihat pada tabel berikut ini :

Tabel 4.5

\section{Hasil Uji f (Simultan)}

\section{ANOVA $^{b}$}

\begin{tabular}{|ll|l|l|l|l|l|}
\hline Model & Sum of Squares & Df & $\begin{array}{l}\text { Mean } \\
\text { Square }\end{array}$ & F & Sig. \\
\hline \multirow{4}{*}{1} & Regressio & 3217299.994 & 3 & 1072433.331 & 13.284 & $.000^{\mathrm{b}}$ \\
$\mathrm{n}$ & Residual & 3632776.257 & 45 & 80728.361 & & \\
\cline { 3 - 5 } & Total & 6850076.251 & 48 & & & \\
\hline
\end{tabular}

a. Dependent Variable: Nilai perusahaan

b. Predictors: (Constant), Hutang berbasis bunga, Ukuran peruahaan, CSR (data diolah)

Untuk menguji apakah model dapat digunakan yaitu membandingkan Sig. pada tabel ANOVA dengan taraf nyatanya (alfa 0,05\%). Jika Sig. > 0,05 maka model ditolak namun jika Sig. $<0,05$ maka model diterima. Pada tabel uji F di atas nilai sig. 0,000 < 0,05 maka dapat disimpulkan model dapat diterima.

Dari hasil analisis regresi dapat diketahui pula bahwa secara bersama-sama variabel independen memiliki pengaruh yang signifikan terhadap variabel 
dependen. Hal ini dapat dibuktikan dari nilai F hitung (13.284) yang lebih besar dari nilai $\mathrm{F}$ tabel $(2,81)$. Model regresi dapat digunakan untuk memprediksi Nilai Perusahaan atau dapat dikatakan bahwa CSR, Ukuran Perusahaan dan IBD secara bersama-sama berpengaruh terhadap Nilai Perusahaan pada perusahaan manufaktur yang terdaftar di JII periode 2010-2016. Sehingga hipotesis yang menyatakan CSR, Ukuran Peusahaan dan IBD secara bersama-sama (simultan) berpengaruh terhadap Nilai Perusahaan pada perusahaan manufaktur yang terdaftar di JII periode 2010-2016 dapat diterima.

\section{Hasil Uji t (Parsial)}

Uji $\mathrm{T}$ bertujuan untuk menguji pengaruh masing-masing variabel independen (CSR, Ukuran Perusahaan, dan Hutang Berbasis Bunga) terhadap variabel dependen (Nilai Perusahaan). Sementara itu secara parsial pengaruh dari ketiga variabel independen tersebut terhadap Nilai Perusahaan ditunjukkan pada tabel berikut:

\section{Tabel 4.6 \\ Hasil Uji t (Parsial) \\ Coefficients ${ }^{a}$}

\begin{tabular}{|c|c|c|c|c|c|c|}
\hline \multirow{2}{*}{\multicolumn{2}{|c|}{ Model }} & \multicolumn{2}{|c|}{$\begin{array}{l}\text { Unstandardized } \\
\text { Coefficients }\end{array}$} & \multirow{2}{*}{$\begin{array}{l}\text { Standardize } \\
\mathrm{d} \\
\text { Coefficients } \\
\text { Beta }\end{array}$} & \multirow[t]{2}{*}{$\mathrm{t}$} & \multirow[t]{2}{*}{ Sig. } \\
\hline & & Std. Error & Std. Error & & & \\
\hline \multirow{4}{*}{1} & (Constant) & 4787.558 & 938.569 & & 5.101 & .000 \\
\hline & Csr & 919.182 & 443.494 & 237 & 2.073 & .044 \\
\hline & ukuran perusahaan & -164.953 & 31.342 & -.585 & -5.263 & .000 \\
\hline & $\begin{array}{l}\text { hutang berbasis } \\
\text { bunga }\end{array}$ & 4414.153 & 1389.361 & .358 & 3.177 & .003 \\
\hline
\end{tabular}

a. Dependent Variable: nilai perusahaan (data diolah)

Pengaruh dari masing-masing variabel CSR, Ukuran Perusahaan dan IBD terhadap Nilai Perushaan dapat dilihat dari arah tanda dan tingkat signifikansi (probabilitas). Variabel CSR mempunyai arah yang positif, sedangkan variabel Ukuran Perusahaan menunjukkan arah negativ dan variabel IBD menunjukan arah positif. Dapat dilihat bahwa variabel CSR berpengaruh terhadap Nilai Perushaan karena tingkat signifikansinya $<0,05$. Hasil pengujian hipotesis masingmasing variabel independen secara parsial terhadap variabel dependennya dapat dianalisis sebagai berikut:

Menunjukkan variabel CSR memiliki t hitung sebesar 2.073 dengan $\mathrm{t}$ tabel sebesar 1,676 dan nilai signifikansi sebesar 0.044. Dimana nilai signifikansinya 
lebih besar dari a atau 0.05 yang menunjukkan bahwa CSR berpengaruh positif dan signifikan terhadap nilai perusahaan, yang berarti

H1 : Corporate social responsibility berpengaruh positif terhadap nilai perusahaan, diterima.

Variabel ukuran perusahaan memiliki t hitung sebesar -5.263 dengan $t$ tabel sebesar 1,676 dan nilai signifikansi 0.000 . Dimana nilai signifikansinya lebih kecil dari a atau 0.05 yang menunjukkan bahwa ukuran perusahaan berpengaruh negatif dan signifikan terhadap Nilai peusahaan yang berarti :

H2 : Ukuran perusahaan berpengaruh Positif terhadap nilai perusahaan, ditolak.

Menunjukkan variabel Interest based debt (hutang berbasis bunga) memiliki t hitung sebesar 3.177 dengan $\mathrm{t}$ tabel sebesar 1,676 dan nilai signifikansi sebesar 0.003. Dimana nilai signifikansinya lebih kecil dari a atau 0.05 yang menunjukkan Hutang berbasis bunga bahwa berpengaruh signifikan dan positif terhadap nilai perusahaan, yang berarti

H3 : Interest Based Debt berpengaruh positf terhadap nilai perusahaan, diterima

\section{Hasil Uji R2 (Determinasi)}

Koefisien determinasi $\left(R^{2}\right)$ pada intinya mengukur seberapa jauh kemampuan model dalam menerangkan variasi variabel dependennya. Nilai Koefisien determinasi $\left(R^{2}\right)$ yang mendekati satu berarti variabel-variabel independennya menjelaskan hampir semua informasi yang dibutuhkan untuk memprediksi variabel dependen (Ghozali, 2005). Hasil perhitungan Koefisien Determinasi penelitian ini dapat terlihat pada tabel berikut:

\section{Tabel 4.7}

\section{Hasil Uji R ${ }^{2}$ Koefisien Determinasi}

\section{Model Summary ${ }^{b}$}

\begin{tabular}{|l|r|r|l|r|r|}
\hline $\begin{array}{l}\text { Mode } \\
1\end{array}$ & R & R Square & $\begin{array}{l}\text { Adjusted R } \\
\text { Square }\end{array}$ & $\begin{array}{l}\text { Std. Error of } \\
\text { the Estimate }\end{array}$ & Durbin-Watson \\
\hline 1 & $.685^{\mathrm{a}}$ & .470 & .434 & 284.12737 & 1.862 \\
\hline
\end{tabular}

a. Predictors: (Constant), Hutang berbasis bunga, Ukuran peruahaan, CSR

b. Dependent Variable: Nilai perusahaan (data diolah)

Adjusted $\mathrm{R}$ square merupakan nilai $\mathrm{R}^{2}$ yang disesuaikan sehingga gambarnya lebih mendekati mutu penjajakan model, dari hasil perhitungan nilai adjusted $\mathrm{R}$ square sebesar 0,434 atau 43.4\%. Maka dapat disimpulkan bahwa CSR, Ukuran perusahaan dan Hutang berbais bunga pengaruh sebesar $43.4 \%$ terhadap Nilai Perusahaan sedangkan sisanya $56.6 \%$ dipengaruhi variabel lain.

SIMPULAN DAN SARAN

Kesimpulan 
Berdasarkan hasil penelitian yang dilakukan oleh peniliti dengan judul “Pengaruh Corporate Social Responsibility (CSR), Ukuran Perusahaan dan Interest Based Debt (IBD), Terhadap Nilai Perusahaan Pada Perusahaan Manufaktur Yang Terdaftar di Jakarta Islamic Index Periode 2010 - 2016" maka dapat ditarik kesimpulan sebagai berikut:

1. Corporate Social Responsibility berpengaruh positif signifikan terhadap Nilai Perusahaan pada perusahaan manufaktur, hasil penelitian ini menunjukkan bahwa besar kecilnya praktik CSR mempengaruhi peningkatan nilai perusahaan. Hal ini sesuai dengan teori bahwa perusahaan bukanlah entitas yang hanya beroperasi untuk kepentingan sendiri namun harus memberikan manfaat bagi stakeholdernya.

2. Ukuran Perusahaan berpengaruh negatif dan signifikan terhadap Nilai Perusahaan pada perusahaan manufaktur, hal ini disebabkan karena pada industri manufaktur memilki aset yang besar namun aset tersebut merupakan asset yang tidak produktif, dimana hal tersebut terlihat pada jumlah aset tidak lancar yang besar sehingga ukuran perusahaan memberikan pengaruh turunnya nilai perusahaan pada sebagian besar industri manufaktur.

3. Interest Based Debt berpengaruh positif dan Signifikan terhadap Nilai Perusahaan pada perusahaan manufaktur. Hasil riset pada variabel ini konsisten dengan temuan MM pada tahun 1963 bahwa dengan memasukan pajak penghasilan perusahaan, maka penggunaan hutang akan meningkatkan nilai perusahaan karena biaya bunga hutang adalah biaya yang mengurangi pembayaran pajak (tax deductable expense).

\section{Saran}

Berdasarkan hasil analisis pembahasan serta beberapa kesimpulan pada penelitian ini, adapun saran-saran yang dapat diberikan melalui hasil penelitian ini, yaitu :

1. Keterbatasan pertama yaitu penelitian ini hanya menggunakan periode pengamatan yang relatif pendek sejak 2010-2016 saja dan cuma menggunakan 1 variabel dependen yaitu Nilai perusahaan. Untuk penelitian selanjutnya sebaiknya menggunakan periode pengamatan yang lebih panjang.

2. Variabel dalam penelitian ini hanya terbatas pada empat variabel yang diteliti sehingga apabila dalam penelitian selanjutnya ada penambahan variabel kemungkinan akan membuat variasi hasil pengamatan yang bisa saling melengkapi.

\section{DAFTAR PUSTAKA}

Brigham \& Houston. Dasar-Dasar Mnajemen Keuangan, Jakarta: Salemba Empat, 2007. 
Christiawan, Yulius Jogi, \& Josua Tarigan, Kepemilikan Manajerial: Kebijakan Hutang, Kinerja dan Nilai Perusahaan. Jurnal Akuntansi dan Keuangan. Vol. 9, No.1, 2007

Fahmi, Irham. Etika Bisnis Teori, Kasus, Dan Kolusi, Bandung: Alpabeta, 2014.

Fajar Nd, Mukti. Tanggung Jawab Sosial Di Indonesia, Yogjakarta: Pustaka Pelajar,2013.

Hasnawati, Sri, Agnes Sawi. Keputusan Keuangan, Ukuran Perusahaan, Struktur Kepemilikan Dan Nilai Perusahaan Publik Di Indonesia. Jurnal, 2015.

Kasmir, Pengantar Manajemen Keuangan, Jakarta: Kencana, 2016.

Raprayogha, Rusdi, Rusnawati, \& Djamila Abbas, Pengaruh Kinerja Keuangan terhadap Harga Saham pada Sektor Industri Barang Konsumsi yang Tercatat di JII. Jurnal Manajemen Ide dan Inspirasi, vol. 4 no. 1, 2017

Safitri, Hazlina, \& Suwitho, Pengaruh Size, Growth, dengan Kebijakan Dividen sebagai Variabel Moderating terhadap Nilai Perusahaan. Jurnal Ilmu dan Riset Manajemen, vol 4, No. 6, Juni 2015

Said, Salmah \& Fadel Muhammad H. 2016. Pengaruh Risiko Kredit Dan Tingkat Kecukupan Modal Terhadap Profitabilitas Pada Perbankan Di Bursa Efek Indonesia. Jurnal Manajemen Ide dan Inspirasi, Vol. 3, No. 2, 2016

Sartono, Agus. Manajemen Keuangan Teori Dan Aplikasi, Yogjakarta: Bpfe, 2016.

Sujoko \& Egi Soebiantoro, Pengaruh Struktur Kepemilikan, Leverage, Faktor Intern dan Faktor Ekstern terhadap Nilai Perusahaan. Jurnal Ekonomi Manajemen, 2007

Syariati, A., \& Syariati, N. E. (2012). Islamic Bank as Bank of Ethics. In Proceeding of Annual South East Asian International Seminar. 


\title{
Penanggung Jawab \\ Ambo Asse
}

\section{Ketua/}

M. Wahyuddin Abdullah

\author{
Dewan Editor \\ Alim Syariati \\ Rusdi Prayoga \\ Andi Mulia \\ Rusnawati
}

\author{
Mitra Bestari/Reviewer \\ Ambo Asse (UIN Alauddin Makassar), \\ Firman Menne (Universitas Bosowa Makassar) \\ Suwandi Ng (Universitas Atma Jaya Makassar), \\ Agus Salim (ISEI Sul-Sel), \\ Rika Dwi Ayu Parmitasari (UIN Alauddin Makassar), \\ Ahmad Efendi (UIN Alauddin Makassar), \\ Awaluddin (UIN Alauddin Makassar), \\ Okta Nofri (UIN Alauddin Makassar), \\ Eka Suhartini (UIN Alauddin Makassar), \\ Akil Rahman (UIN Alauddin Makassar),
}

\author{
Sekretaris Penyunting \\ Rusmawandi Rara \\ Nurhikma Hawabaja \\ Roshani
}

\author{
JURNAL MINDS \\ Pusat Dokumentasi dan Publikasi IImiah \\ Jurusan Manajemen Fakultas Ekonomi dan Bisnis Islam UIN Alauddin \\ JI. Sultan Alauddin No. 33 Samata-Gowa Sul-Sel -- INDONESIA \\ Telp/HP. 081355774774, 081241840208, Fax. (0411) 8221400 \\ Website OJS: http://journal.uin-alauddin.ac.id/index.php/minds \\ Email: minds@uin-alauddin.ac.id
}




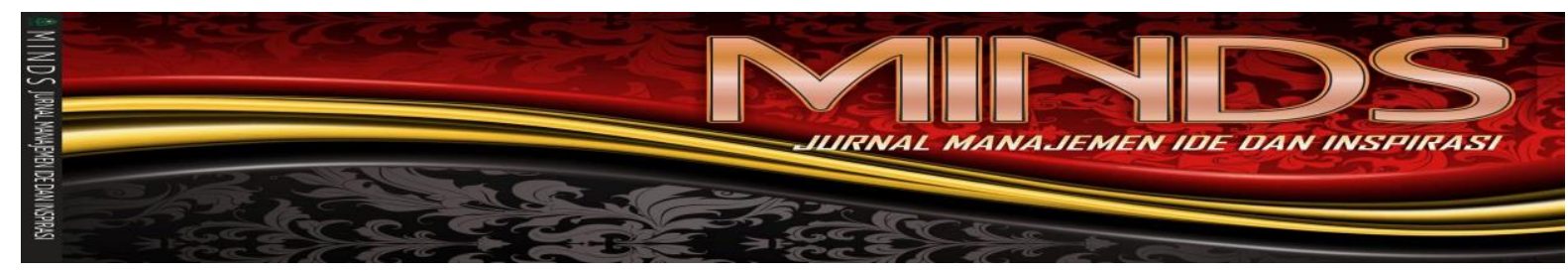

\section{KRITERIA TULISAN}

1. Panjang tulisan minimal 10 halaman dan maksimal 15 halaman

2. Menggunakan huruf Book Antiqua, font 12 , spasi 1, margin atas-bawah $3 \mathrm{~cm}$, kiri-kanan $2.54 \mathrm{~cm}$.

3. Tulisan dapat berupa hasil penelitian kuantitatif (diutamakan), penelitian kualitatitif, dan kajian teoritis dalam bidang Manajemen dengan penguatan pada integrasi keislaman.

4. Identitas penulis meliputi: nama penulis tanpa gelar, nama dan alamat afiliasi, dan alamat email penulis (contoh Alim Syariati, Fakultas Ekonomi dan Bisnis Islam UIN Alauddin, JI. HM. Yasin Limpo, NO. 63 Samata-Gowa, alim.syariati@uin-alauddin.ac.id).

5. Komposisi tulisan harus mengikuti pola berikut:

a. Judul

b. Abstrak (bahasa Indonesia dan bahasa Inggris) maksimal 150 kata dan kata kunci 3-5 kata

c. Pendahuluan (Yang didalamnya menyinggung mengenai masalah penelitian)

d. Tinjauan teoritis

e. Metode penelitian

f. Pembahasan

g. Penutup

h. Daftar pustaka

Buku: Hartono, Jogiyanto, 2004. Metodologi Penelitian Bisnis: Salah Kaprah dan pengalaman-pengalaman. Edisi 2004/2005. BPFE, Yogyakarta

Jurnal: Barney, Jay B. 1995. Looking Inside Competitive Advantage. Academy of Management, pp. 49-61

Penelitian Tidak Publikasi: Minimal sumber referensi berasal dari disertasi S3 (tapi tidak dianjurkan), dengan mengikuti format di atas

6. Menggunakan Innote

7. Waktu penting dalam penerbitan Jurnal berkala IImiah Minds, yaitu bulan Maret- Mei untuk terbitan pertama tahun berjalan, dan Oktober-November untuk terbitan kedua tahun berjalan melalui online journal system (OJS) yang bisa diakses melalui laman http://journal.uin-alauddin.ac.id/index.php/minds. Pertanyaan terkait jurnal Minds bisa disampaikan melalui email: minds@uin-alauddin.ac.id atau alim.syariati@uinalauddin.ac.id 